\title{
ESTUDO DO TEMPO DE MEIA VIDA DA LIPASE B DE Candida antarctica LIVRE E IMOBILIZADA EM ESPUMA FLEXÍVEL DE POLIURETANO DE DIFERENTES DENSIDADES ESTOCADAS A ALTAS TEMPERATURAS
}

\author{
ANTUNES, A. ${ }^{1}$, FICANHA, A. M. M. ${ }^{1}$, NYARI, N.L.D. ${ }^{1}$, ZAMADEI, R. ${ }^{1}$, M. BOPSIN ${ }^{1}$, K. L. \\ LEVANDOSKI $^{1}$, A. R. PAULAZZI ${ }^{1}$, ZENI, J. ${ }^{1}$, DALLAGO, R.M. ${ }^{1}$ \\ ${ }^{1}$ Universidade Regional Integrada do Alto Uruguai e das Missões - Campus de Erechim, \\ Departamento de Engenharia de Alimentos, Erechim, Rio Grande do Sul, Brasil E-mail para contato: \\ nenaantunes@gmail.com
}

\begin{abstract}
RESUMO - A tecnologia enzimática é uma alternativa que visa substituir os processos químicos, uma vez que os biocatalisadores envolvem processos com menor impacto ambiental, são mais específicos, e apresentam-se como uma ferramenta promissora para síntese de compostos de alto valor agregado. A lipase de Candida antarctica B (CALB) é conhecida por sua eficiência e elevada seletividade, utilizada em uma gama de aplicações e na substituição de processos sintéticos industriais. $\mathrm{Na}$ forma imobilizada, esta enzima, oferece algumas vantagens operacionais, como na escolha de processos descontínuos ou contínuos, tempo de reação, controle do processo. A imobilização pelo método de confinamento ou por ligações covalentes em situ em espuma flexível de poliuretano de densidade D30 e D18, utilizada neste estudo é uma técnica confiável para contornar a lixiviação e para aumentar a estabilidade da enzima imobilizada. Desta forma, o objetivo do trabalho foi avaliar o tempo de estocagem da lipase de Candida antarctica do tipo B livre e imobilizada em espuma flexível de poliuretano (PU) de diferentes densidades (D30 e D18) submetidas a altas temperaturas $\left(40,60\right.$ e $\left.80{ }^{\circ} \mathrm{C}\right)$. Após 180 dias, as amostras ainda apresentam atividade residual de $30 \%$, para todas as temperaturas. A quantificação da atividade de esterificação foi realizada por titulometria. A exposição a altas temperaturas resultou em resultados que demonstram que a utilização de espumas de poliuretano, como suporte na imobilização de enzimas, resulta em um aumento da estabilidade. Os resultados mostram que esse biocatalisador pode ser aplicado na síntese contínua de ésteres utilizando-se reatores de leito fixo em diferentes temperaturas reacionais.
\end{abstract}

\section{INTRODUÇÃO}

As lipases são reconhecidas como o mais importante grupo de biocatalisadores devido à sua ampla gama de substratos e meios de reações com uma elevada seletividade, especificidade e versatilidade, Essa habilidade é conhecida como "promiscuidade enzimática", apresentando importância em hidrolisar óleos e gorduras no tratamento de efluentes com alto teor de gordura e atuarem na interface orgânico-aquoso (Mendes e Castro 
2013). No entanto a utilidade lipases continua a ser um desafio significativo, por seres sensíveis, instáveis e insolúveis em solventes orgânicos. Para isso a tecnologia de imobilizar enzimas ganhou impulso, no que se refere na facilidade de separação dos produtos, reutilização, eficiência catalítica, estabilidade e redução nos custos do processo (Sheldon e Van Pelt, 2013).

Sendo assim, os poliuretanos têm sido investigados principalmente na utilização como suportes enzimáticos, onde a enzima fica retida na estrutura porosa da matriz. Por possuir certa flexibilidade e com variedade de compostos diferentes de propriedades físicas, químicas e morfológicas de acordo com necessidades específicas de aplicação (Albiquim, 2014). Entretanto o objetivo desse estudo foi avaliar o processo de imobilização in situ em suporte em espuma flexível de Poliuretano (PU) de densidade D30 e D18, utilizando a proporção dos monômeros, surfactantes, extensores de cadeia e água, bem como a estabilidade de operação submetidas a altas temperaturas $\left(40,60\right.$ e $\left.80^{\circ} \mathrm{C}\right)$, da enzima livre e imobilizada e seus respectivos reusos.

\section{MATERIAIS E MÉTODOS}

\subsection{Procedimento de Imobilização}

O procedimento experimental para imobilização da Candida antarctica B (CAL B) em espuma flexível de PU de densidade 30 e 18, foi realizada utilizando a proporção dos monômeros, surfactantes, extensores de cadeia e água, proporções essa cedidas pela empresa Tasca Estofados e Cia (empresa produtora de espuma flexível de poliuretano), a qual também ofertou as matérias primas para a fabricação da espuma flexível de PU.

O emprego da enzima foi em estado líquido, com preparo de solução enzimática ( $2 \mathrm{~g}$ em $20 \mathrm{~mL}$ de água destilada). O imobilizado foi produzido pela mistura da enzima em solução (correspondendo a 10 \% do volume total dos monômeros).

Cabe ressaltar que o método de imobilização utilizado nesta pesquisa consiste no método de encapsulamento, onde ocorre a formação de uma estrutura porosa na presença da enzima, envolvendo-a em uma estrutura tridimensional, realizando o "confinamento" da proteína no polímero insolúvel, resultando no biocatalisador imobilizado (Dalla-Vecchia et al., 2004; Gonçalves, 2007).

\subsection{Atividade Enzimática-Esterificação}

A atividade de esterificação das foi realizada pela quantificação da reação de síntese do ácido oleico e etanol (razão molar $1: 1(\mathrm{v} / \mathrm{v})$ ). A reação foi conduzida a $40{ }^{\circ} \mathrm{C}, 160 \mathrm{rpm}$ por 40 min. Esta foi iniciada pela adição da enzima $(0,1 \mathrm{~g})$ ao meio reacional, em frascos de vidro com tampa, mantidos em agitador orbital. Alíquotas de $500 \mu \mathrm{L}$ foram retiradas do meio reacional em triplicata no início da reação. A cada amostra foram adicionados $15 \mathrm{~mL}$ de uma solução de acetona-etanol (1:1) (v/v) para paralisar a reação e para extração de éster de oleato de etila segundo Paroul et al (2010 e 2011). A quantidade de ácido consumida foi determinada por titulação com $\mathrm{NaOH} 0,05 \mathrm{M}$ até $\mathrm{pH} 11$. Uma unidade de atividade enzimática foi definida como a quantidade de enzima que consome $1 \mu \mathrm{mol}$ de ácido graxo por minuto, nas condições do ensaio. A atividade enzimática foi calculada baseando em Brígida et al., 2010). 


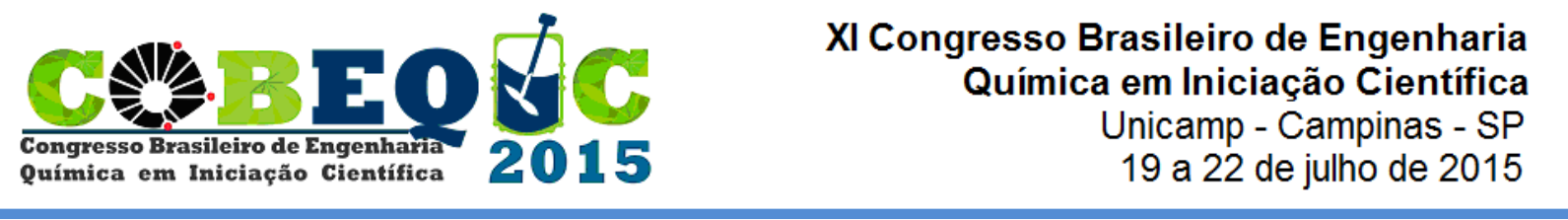

\subsection{Cálculo do Rendimento de Imobilização}

O rendimento do imobilizado foi calculado considerando a atividade total da enzima livre em solução (volume de extrato enzimático empregado no ensaio de imobilização) e a atividade total do imobilizado (massa total de imobilizado produzido) (Brígida et al., 2010).

\section{RESULTADOS E DISCUSSÕES}

\subsection{Avaliação da estabilidade térmica da CALB livre}

O estudo da estabilidade de estocagem é importante, pelo fato de permitir observar o comportamento da enzima e quanto de sua atividade inicial é mantida ao longo do tempo de armazenamento nas diferentes temperaturas.

Inicialmente fez-se o estudo da estabilidade de estocagem da lipase na sua forma livre e observa-se uma diminuição da atividade com o tempo de contato para todas as temperaturas avaliadas, bem como uma relação direta com a temperatura. As maiores temperaturas apresentaram desativações mais rápidas. Para a temperatura de $80^{\circ} \mathrm{C}$ a inativação foi total com 6 horas de contato. Para as temperaturas de 60 e $40^{\circ} \mathrm{C}$ a inativação total somente foi observada com $72 \mathrm{~h}$ de contato para ambas como mostrado na Figura 1.

Figura 1 - Estabilidade de estocagem frente e altas temperaturas para a Lipase B de Candida antarctica

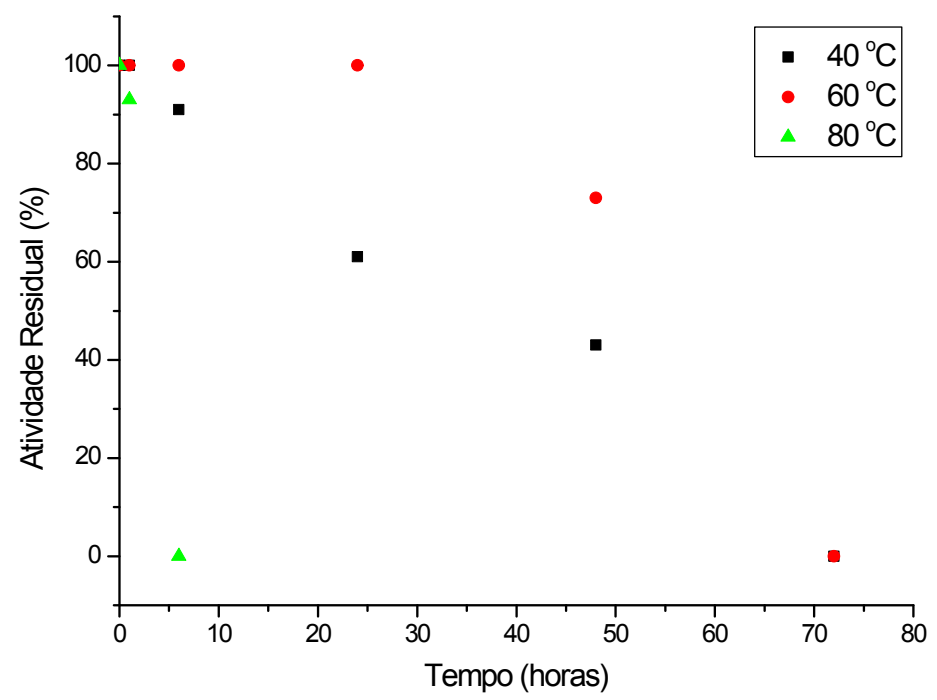

\subsection{Avaliação da estabilidade térmica da CALB de densidade 30 e 18}

A Figura 2 apresenta a estabilidade de estocagem frente a altas temperaturas para a enzima imobilizada em poliuretano de densidade D30 (a) e 18 (b), respectivamente.

Figura 2 - Estabilidade de estocagem em altas temperaturas para a enzima imobilizada em poliuretano de densidade D30 e 18 

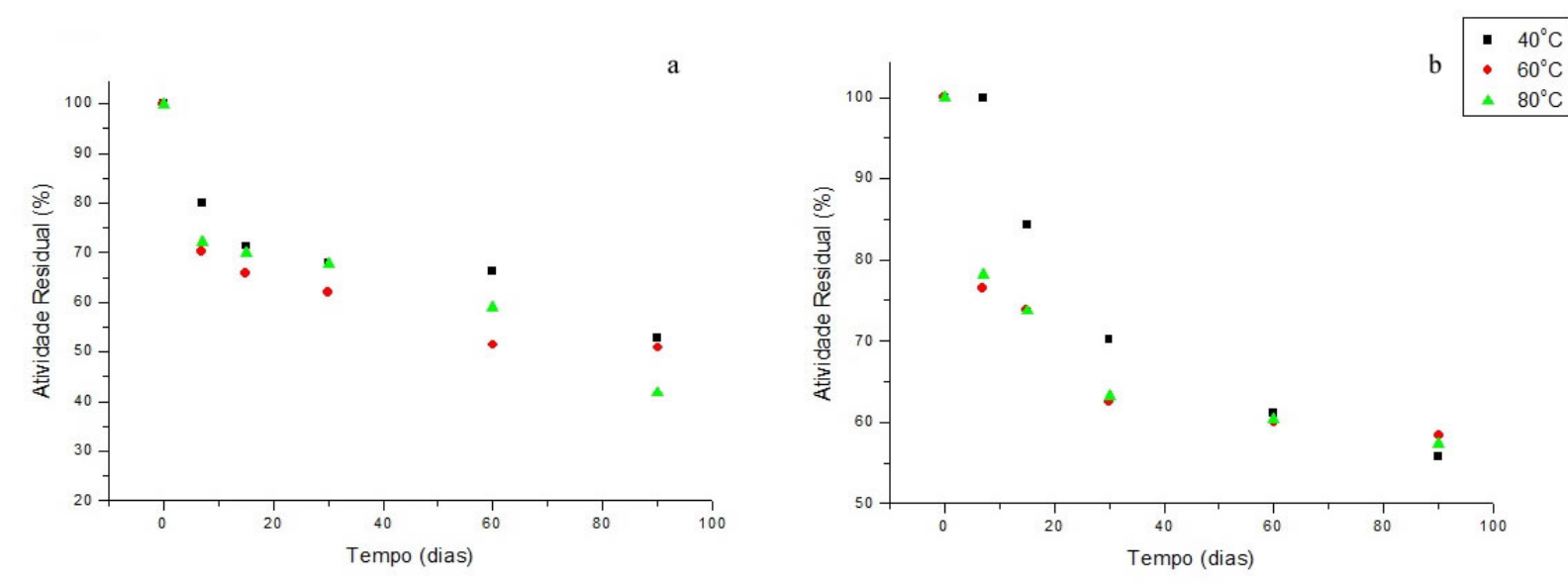

De acordo com a enzima imobilizada em poliuretano de densidade D30 (Figura 2a), a qual apresentou o mesmo comportamento ao longo do tempo para todas as temperaturas de estocagem estudadas $\left(40,60\right.$ e $\left.80{ }^{\circ} \mathrm{C}\right)$ manteve-se acima de $50 \%$ no mesmo período, podendose assim concluir que a enzima imobiliza em poliuretano de densidade D30 é estável a temperaturas altas temperaturas.

Como pode ser observado a enzima imobilizada em poliuretano de densidade D18 (Figura 2b) apresentou o mesmo comportamento ao longo do tempo para todas as temperaturas de estocagem estudadas, porém quando a enzima imobilizada foi submetida a temperatura estocagem igual a $60^{\circ} \mathrm{C}$, esta apresentou a maior queda de atividade residual $(50 \%)$ em apenas 60 dias, seguida da $40^{\circ} \mathrm{C}$ em 90 dias é possível concluir que a enzima imobilizada em poliuretano de densidade D18 é mais estável em temperatura de $80^{\circ} \mathrm{C}$.

O experimento usando a enzima CAL B imobilizado em Accurel (polipropileno) e poliestireno aumentou de três vezes no tempo de estabilidade em relação a enzima livre, que apresentou um tempo de meia vida de apenas 5 dias (Blanco et al., 2004).

Yilmaz et al. (2010; 2011), observou que as lipases de Candida rugosa imobilizadas em matriz sol-gel mantinham uma atividade residual de $\approx 90 \%$ por 50 dias quando armazenadas a $4{ }^{\circ} \mathrm{C}$ enquanto a enzima livre, após 12 dias apresentou $15 \%$ da atividade residual.

\section{CONCLUSÃO}

A utilização de espumas flexível de poliuretano, exposta a altas temperaturas demonstram que como suporte na imobilização de enzimas tem eficácia, pois como resposta, houve um aumento da estabilidade. Os resultados mostram que esse biocatalisador pode ser aplicado na síntese contínua de ésteres utilizando-se reatores de leito fixo em diferentes temperaturas reacionais.

\section{REFERÊNCIAS BIBLIOGRÁFICAS}

ALBIQUIM, Associação Brasileira da Indústria Química, disponível em: http://ebiquim.org.br, acesso em 20 de fevereiro de 2014. 
BRÍGIDA, A. I. S. Imobilização de lipases utilizando fibra da casca de coco verde como suporte para aplicações industriais, Tese de Doutorado, Universidade Federal do Rio de Janeiro, Rio de Janeiro, RJ, 2010.

BlANCO, R. M.; TERREROS, P.; PÉREZ, M. F.; OTERO, C.; GONZÁleZ, G., Functionalization of mesoporous silica forlipase immobilization characterization of the support and the catalysts. J. Mol. Catal. B. Enzym., v. 30, p. 83-93, 2004.

DALLA-VECCHIA R.; NASCIMENTO, M. DA G.; SOLDI, V. Aplicações sintéticas de lipases imobilizadas em polímeros. Quím. Nova, v. 27, p. 623-630, 2004.

MENDES, A. A., CASTRO, H. F. D.; PEREIRA, E. B.; FURIGO JÚNIOR, A. Aplicação de lipases no tratamento de águas residuárias com elevados teores de lipídeos. Quím. Nova, v. 28, p. 296-305, 2013.

SHELDON, R..; VAN PELT, S. Enzyme immobilisation in biocatalysis: Why, what and how. Chem. Soc, v. 42, p. 6223-6235, 2013

YILMAZ, E., SEZGIN, M.; YILMAZ, M. Immobilization of Candida rugosa lipase on magnetic sol-gel composite supports for enzymatic resolution of (R,S)-Naproxen methyl ester. J. Mol. Catal. B. Enzym., v. 69, p. 35-41, 2011.

YILMAZ, E.; SEZGIN, M.; YILMAZ, M. Enantioselective hydrolysis of rasemic naproxen methyl ester with sol-gel encapsulated lipase in the presence of sporopollenin. J. Mol. Catal. B. Enzym., v. 62, p. 162-168, 2010.

GONÇALVES, F. A. G. Produção de lipase extracelular por leveduras em cultivo submerso. Belo Horizonte, Dissertação de Mestrado. Departamento de Ciências de Alimentos da Universidade Federal de Minas Gerais. 2007

PAROUL, N.; BIASI, A.; ROVANI, A. C.; PRIGOL, C.; DALLAGO, R.; TREICHEL, H.; OLIVEIRA, D. Enzymatic production of linalool esters in organic and solvent-free system. Bioprocess Biosyst. Eng., v. 33, p. 583-589, 2010.

PAROUL, N.; GRZEGOZESKI, L. P.; CHIARADIA, V.; TREICHEL, H.; CANSIAN, R. L.; OLIVEIRA, J. V.; OLIVEIRA, D. Solvent-free geranyloleate production by enzymatic esterificarion. Bioprocess Biosyst. Eng., v. 34, p. 323-329, 2011. 